\title{
Projeto Ficção Cientifica: mito ou realidade? Trabalhando Gênero Textual de Forma Colaborativa
}

\author{
Jaiane Ramos Barbosa ${ }^{1}$, Maria Auricélia da Silva ${ }^{1}$, José Aires de Castro Filho ${ }^{1}$ \\ ${ }^{1}$ Instituto UFC Virtual, Universidade Federal do Ceará (UFC). Campus do \\ Pici, bloco $901-1^{\circ}$ andar, CEP: 60.455-760 \\ \{jaiane, auricelia.silva, aires\}@virtual.ufc.br
}

\begin{abstract}
This work objectives to present how the collaborative project titled Scientific Fiction :Myth or Reality? developed in a school participating within the project One Computer per Student (UCA), contributed to the development of collaborative practices with the use of the laptop within the schoolroom to the work with textual gender in the class of Portuguese Language. The research used the method case study and had a qualitative nature.The situations developed during the Project were made easy with the use of the laptop and its possibilities of mobility and connection, that made possible the activities within the collaborative ambient used.
\end{abstract}

Resumo. A presente pesquisa objetiva apresentar como o projeto colaborativo intitulado Ficção Cientifica: Mito ou Realidade?, desenvolvido em uma escola participante do Projeto Um Computador por Aluno (UCA), contribuiu para o desenvolvimento de práticas colaborativas com o uso do laptop em sala de aula para o trabalho com gênero textual na disciplina de Língua Portuguesa. A pesquisa utilizou o método estudo de caso e teve caráter qualitativo. As situações desenvolvidas durante o Projeto foram facilitadas pelo uso do laptop e suas possibilidades de mobilidade e conexão, que proporcionaram a realização de atividades nos ambientes colaborativos usados.

\section{Introdução}

A sociedade atual passou por diversas transformações impulsionadas pelos avanços tecnológicos ocorridos nas últimas décadas. Sendo assim, os mais diferentes setores da sociedade, tais como economia, política e educação, com o passar dos anos, sofreram alterações e foram modificados (CASTELLS, 1999).

Dentre os diversos setores influenciados pela chegada e permanência da tecnologia, daremos ênfase ao setor educacional que vem sendo, atualmente, bastante analisado, pesquisado e financiado por empresas privadas e pelo Governo Federal, por acreditarem que o espaço escolar também deve acompanhar o modo de viver das crianças e dos adolescentes da geração atual.

Quando relacionamos o termo tecnologia ao setor educacional, logo imaginamos salas de aula modernas, equipadas com lousa digital, animações em 3D, computadores ou tablets disponíveis para alunos e professores, além de profissionais capacitados para o uso das Tecnologias Digitais da Informação e Comunicação (TDIC) na sua dinâmica escolar, mas esse pensamento, na maioria das vezes, não representa, de fato, a realidade 
das escolas brasileiras, sejam elas particulares ou públicas.

Algumas pesquisas indicam que parte dos professores não utiliza de forma satisfatória a tecnologia digital nas suas atividades educacionais, em benefício dos conteúdos curriculares e, consequentemente, como meio facilitador da aprendizagem de seus alunos, uma vez que o computador pode ser usado para desenvolver ações que, dificilmente, poderiam ser realizadas sem seu uso (ALMEIDA; VALENTE, 2011).

Em seus estudos, Almeida (2011) revela dificuldades dos docentes em relação ao uso das tecnologias presentes na escola, à necessidade de formação apropriada e específica, às alterações na estrutura física da escola e às mudanças curriculares que permitam essa inserção.

O formato do ensino brasileiro ainda reflete uma educação bancária e instrucionista, moldada no ensino tradicional. Nessa perspectiva, o professor é detentor de todo o conhecimento e único transmissor do conteúdo, enquanto o aluno é somente um mero receptor de informações e vítima das [...] "proposições tradicionais do ensino, centradas única e exclusivamente na transmissão do conhecimento e no acúmulo de listas infindáveis de conhecimento" (COLL et al.,1998, p. 9/10).

Esse acúmulo de informações gera, em alguns casos, a memorização de dados por meio da estratégia de repetição e decoração. Nesse sentido, os dados apreendidos pelos alunos são facilmente esquecidos quando não revisados e praticados constantemente.

Sobre isso, Coll et al. (1998, p. 28) cita o seguinte exemplo: "Esquecemos o número do telefone do restaurante, quando deixamos de frequentá-lo. Ou os elementos da tabela periódica, quando alguém deixa de nos perguntar por eles". Geralmente, esses dados são decorados apenas com objetivo de o aluno alcançar boas notas nas avaliações escolares.

Sobre isso, Behrens (2005, p.76) afirma que o paradigma conservador/ tradicional é baseado na transmissão de conhecimentos e informações pelo professor, na memorização pelos alunos e numa aprendizagem competitiva e individualista entre esses indivíduos.

Entretanto, o modelo tradicional de ensino diverge do perfil dos alunos presentes em nossas escolas, uma vez que o contato com o universo digital é cada vez mais frequente no dia a dia desses sujeitos, dentro e fora da escola. Tendo em vista a facilidade de acesso, os pertencentes a essa nova geração acabam tornando-se produtores de conteúdos e conhecimentos, por meio dos processos de criação, compartilhamento e divulgação de informações na internet.

Essas funcionalidades são oportunizadas pela presença da Web 2.0, considerada como a segunda geração da web, que se caracteriza por potencializar as formas de publicação, compartilhamento e organização de informações, além de ampliar os espaços para a interação entre os participantes do processo (PRIMO, 2007, p. 1).

De acordo com Pontes (2011 p.17), "A Web 2.0 é caracterizada pela evolução da internet que proporciona meios colaborativos, nos quais os usuários podem ser emissores e receptores, alimentando a interatividade e a socialização, ao contrário do que pregava a Web 1.0, onde a estrutura da internet era estática".

Essa nova geração da web enfatiza a participação e a colaboração do usuário, diferentemente da restrita função de consumidor apresentada pela Web 1.0. Primo (2007) destaca que a Web 2.0 refere-se às possibilidades de utilizar a internet para 
publicar, compartilhar e organizar informações, além de oportunizar um espaço de interação entre os usuários.

Ressaltamos que uma das características principais da Web 2.0 é a possibilidade de todas essas funcionalidades serem desenvolvidas e armazenadas nas nuvens, na rede mundial de computadores, mais precisamente na "internet". Dando ênfase a essa mudança de paradigma, relacionada ao perfil social e ao advento da Web 2.0, constantemente crianças e adolescentes fazem uso de ambientes, aplicativos e ferramentas virtuais de cunho colaborativo, como Twitter, blog, aplicativos do Google Drive, Google +, Facebook, Instagram, WhatsApp, Wikipédia, dentre outros.

Mesmo essa utilização, muitas vezes não sendo destinada ao uso pedagógico, acaba por influenciar o meio educacional, pois essa maneira contemporânea de buscar e produzir informações reflete, também, no cotidiano pessoal e escolar podendo ser inserida e trabalhada em favor da aprendizagem.

Ao analisarmos o novo perfil dos educandos, entendemos que as escolas, também, devem acompanhar esses avanços e transformações. Percebemos a necessidade de uma transformação no modo de ensinar e, consequentemente, de aprender dos sujeitos envolvidos no processo de aprendizagem.

Nessa perspectiva, observamos que atividades desenvolvidas colaborativamente entre estudantes (uns com os outros) e professores (alunos-professor) podem proporcionar um ambiente mais rico e favorável ao processo de ensino e aprendizagem.

Pesquisas apontam que os estudantes apresentam maior interação com o outro por meio do estímulo do trabalho colaborativo ou em equipe (DAMIANNI; SCHELEMMER, 2009; COLL et al., 1998; ZABALA, 1998). Em alguns casos, a utilização e as interações ocorridas entre usuários de plataformas ou ambientes virtuais também apresentam bons resultados.

Assim, entendemos que situações de aprendizagem que enfatizam o individualismo acabam limitando possibilidades de aprendizagem. Um aluno que apresenta dificuldade na assimilação do conteúdo de uma determinada matéria e não demonstra para os outros alunos ou professor essa limitação acaba internalizando tais dificuldades durante todo o percurso, o que ocasiona resultados negativos representados por notas baixas nas avaliações escolares.

Por outro lado, quando esse mesmo aluno é estimulado a participar de situações de aprendizagem em equipe, com vertente colaborativa, acabam surgindo mais possibilidades e situações favoráveis para que ele desenvolva diversos conteúdos, aprenda com o outro e também lhe ensine algo.

Nesse sentido, "a interação com um parceiro mais competente tem se mostrado muito eficiente na indução do desenvolvimento cognitivo" (MOLL, 2005, p. 154). A tecnologia, nesse context, pode ser um elemento facilitador, capaz de favorecer esse processo, levando em conta o perfil atual dos educandos.

Desse modo, a presente pesquisa objetiva apresentar como o projeto colaborativo intitulado Ficção Cientifica: mito ou realidade?, desenvolvido em uma escola participante do projeto Um Computador por Aluno (UCA), contribuiu para o desenvolvimento de práticas colaborativas com o uso do laptop em sala de aula para o trabalho com gênero textual na disciplina de Língua Portuguesa. 


\subsection{O Projeto UCA}

O Projeto UCA baseia-se na proposta da Organização One Laptop per Children (OLPC), dirigida por Nicholas Negroponte, que objetivava distribuir laptops de baixo custo, do tipo XO, a crianças de países em desenvolvimento, a fim de promover a inclusão digital.

No Brasil, essa proposta foi apresentada, ainda no ano de 2005, ao então presidente do país, durante sua participação no Fórum Econômico Mundial de Davos, na Suíça. A concepção do Projeto UCA no Governo brasileiro tomou como base o projeto da OLPC, mas adequou sua proposta em favor da promoção da inclusão digital dos alunos das escolas públicas brasileiras a partir da inserção de laptops educacionais nas salas de aula.

O pesquisador Nicholas Negroponte, do Instituto de Tecnologia de Massachussets (MIT), juntamente com outros pesquisadores, membros da OLPC, estiveram no Brasil, em 2005, para expor a concepção do projeto (SILVA, 2011, p. 17). Logo no ano seguinte, em junho de 2006, o Projeto Um Computador por Aluno (UCA) foi oficialmente lançado.

Em seguida, no ano de 2007, o Governo brasileiro iniciou a fase Pré-piloto do Projeto, composta pelos processos burocráticos e licitatórios para compra dos laptops. Somente em janeiro de 2010, iniciou-se a fase piloto do Projeto por meio da distribuição de laptops para 300 escolas brasileiras.

Experiências utilizando o laptop já vinham sendo realizadas em outros países, como Portugal, Espanha, Paraguai, Argentina, Uruguai e Estados Unidos da América (EUA). Nesses países, o objetivo principal do projeto era promover a inclusão digital de crianças e jovens, porém, no Brasil, seu objetivo adquiriu uma vertente mais pedagógica, enfatizando o uso educacional (BRASIL, 2008).

A implementação e concretização desse projeto no Brasil significou o início de um novo momento histórico da Informática Educativa no país, pois o laptop entrou na sala de aula regular e começou a ser usado, assim como o livro didático, lápis, caderno e lousa.

Na próxima sessão, comentaremos a metodologia utilizada na coleta de dados, que será seguida da apresentação dos resultados e discussões acerca do Projeto Colaborativo Ficção Cientifica: mito ou realidade?. Ao final, as conclusões serão expostas.

\section{Procedimentos Metodológicos}

A presente pesquisa utilizou o método estudo de caso e teve caráter qualitativo, ocorreu em uma das nove escolas contempladas com o projeto UCA no estado do Ceará.

\subsection{Local e participantes}

A pesquisa foi realizada com uma turma do $8^{\circ}$ ano do Ensino Fundamental da Escola de Ensino Fundamental PAS, localizada no distrito de Parada, no município de São Gonçalo do Amarante, no estado do Ceará.

O projeto teve duração de, aproximadamente, três meses (com os alunos), em que foram realizados 10 encontros presenciais e uma aula de campo destinada à visitação dos alunos e professores a X Bienal Internacional do Livro de Fortaleza, Ceará. 
O Projeto Ficção Cientifica: mito ou realidade?, aqui investigado, englobou seis disciplinas curriculares, quais sejam: Língua Portuguesa, Literatura, Matemática, Ciências, Geografia e Inglês. No entanto, durante as discussões do artigo, daremos ênfase somente às atividades realizadas na disciplina de Língua Portuguesa.

Os encontros com os alunos para o desenvolvimento do projeto, em Língua Portuguesa, ocorreram uma vez por semana e os temas curriculares discutidos e trabalhados durante a realização das atividades do projeto tiveram como foco as discussões do livro Viagem ao Centro da Terra, do autor francês Júlio Verne.

A escolha do referido livro para subsidiar as atividades do referido projeto foi sugerida pela professora da disciplina de Língua Portuguesa. A indicação da obra se deu pelo fato de a disciplina Língua Portuguesa, do terceiro bimestre do $8^{\circ}$ ano, apresentar o conteúdo programático ficção científica como gênero textual. Nesse sentido, todas as atividades previamente planejadas apresentavam interligações com conteúdos e situações presentes no livro adotado.

Além das atividades realizadas com o uso do laptop, a professora de Língua Portuguesa, objetivando trabalhar com o projeto em diversos momentos da sua disciplina, inseriu os temas abordados na avaliação bimestral.

\subsection{Materiais usados}

Durante o desenvolvimento da pesquisa, utilizamos como instrumentos principais o laptop educacional conectado à internet, ferramentas livres do Google Drive e o Sistema Online para Criação de Projetos e Comunidades (Sócrates).

O ambiente colaborativo Sócrates (http://www.virtual.ufc.br/socrates), baseado na $W e b$, foi idealizado e desenvolvido pelo grupo Humanas da Universidade Federal do Ceará. Esse ambiente possibilita a criação de projetos, comunidades e cursos de aprendizagem em que os integrantes podem acessar suas funcionalidades de forma online, quando conectados à internet (CASTRO FILHO et al., 2007). No caso do projeto aqui investigado, utilizamos a função Projeto.

A partir das situações colaborativas propostas durante os encontros presenciais e no ambiente virtual, os alunos usaram os laptops, a fim de construir materiais digitais e promover interação e colaboração entre os participantes do projeto.

Esses momentos serviram para promover a criação colaborativa de materiais digitais, como textos em wikis, Google Docs, criação e edição de imagens, gravação de áudio e vídeo, captura de imagens com a webcam, entre outros.

Também foram utilizadas outras ferramentas do ambiente Sócrates, a fim de promover a comunicação e a interação síncrona e assíncrona entre os alunos por meio do email, chat, fóruns, diário de bordo e mensagens.

Utilizamos como técnicas e materiais de coleta de dados: 1) diário de campo; 2) entrevista semiestruturada; 3) gravação de vídeo, áudio e captura de imagens coletadas pelos próprios pesquisadores.

A análise dos dados e as situações vivenciadas junto aos envolvidos no projeto permitiu reunir algumas contribuições que foram consideradas relevantes para o processo de ensino e aprendizagem com o uso do laptop. A seguir, apresentaremos nossas conclusões acerca das análises aqui realizadas. 


\section{Resultados e Discussão}

O principal objetivo do Projeto Ficção Científica: mito ou realidade? foi proporcionar a realização de atividades colaborativas com o uso do laptop educacional e de ferramentas online e off-line.

As atividades realizadas durante o projeto foram pensadas e planejadas previamente pelos professores da escola, por meio da interligação das atividades com os conteúdos curriculares propostos na matriz curricular do semestre.

Como citado anteriormente, a ênfase recaiu sobre as atividades desenvolvidas no âmbito da disciplina Língua Portuguesa. Como produto final, os alunos produziram uma coletânea de contos de ficção científica, que pode ser acessada através do endereço eletrônico http://www.calameo.com/read/00152285454d3ee440fa9.

A seguir, apresentaremos as etapas do projeto, nas quais foi trabalhado o gênero textual ficção científica de forma colaborativa.

\subsection{Etapas iniciais do Projeto}

Todas as atividades previamente planejadas e desenvolvidas durante o Projeto seguiram uma vertente colaborativa. Nesse sentido, até a escolha do nome do projeto foi feita de forma colaborativa, com o envolvimento de todos os participantes.

No início, foi construída uma enquete online objetivando escolher o nome do projeto. Após a apresentação da proposta e do objetivo do projeto aos alunos, eles sugeriram diversos nomes.

Objetivando escolher de forma democrática, os nomes sugeridos foram inseridos no Google Drive na função formulário. Em seguida, os alunos envolvidos no projeto votaram na opção que julgaram mais interessante.

O resultado dessa votação foi apresentado na forma de gráficos, ferramenta planilha, também do Google Drive. O nome mais votado pelos alunos foi Ficção Cientifica: mito ou realidade?

\subsection{Produções textuais realizadas durante o projeto Ficção Cientifica: mito ou realidade?}

As atividades realizadas durante o projeto colaborativo também foram realizadas de forma off-line com e sem o uso da tecnologia digital, como nos casos de uso do programa de editor de áudio, imagens no Tux Paint, editor de apresentação Impress, uso da câmera do laptop e trabalhos manuais.

Várias foram as atividades propostas durante o projeto em que os alunos deveriam produzir textos usando a ferramenta de texto do próprio laptop. Entre elas, podemos citar a atividade em que os alunos produziram um texto coletivo sobre o filme Viagem ao Centro da Terra, escrita de um artigo de opinião sobre o tema tecnologia, construção do roteiro de uma peça teatral que seria encenada na culminância do projeto e a digitação dos contos de ficção científica que, posteriormente, tornar-se-iam uma coletânea.

Atentando para a construção da coletânea de contos de ficção científica produzidos pelos alunos, foi lançado um concurso de desenho para escolher a capa que ilustraria o livro produzido por eles. Logo que lançada a ideia, os alunos ficaram livres para criar suas produções. 
Alguns alunos desenharam à mão, outros usaram o software Tux Paint para inserir e editar imagens e alguns alunos coletaram imagens na internet e fizeram montagens usando o Impress.

A coletânea de vinte e um (21) contos produzidos pelos alunos foi ilustrada com todas as produções dos estudantes que participaram do concurso. Os desenhos feitos à mão foram escaneados e inseridos no arquivo digital que, posteriormente, foi impresso e disponibilizado também na internet.

Somente na culminância do projeto, os alunos ficaram sabendo qual foi o desenho escolhido para ser a capa da coletânea de contos. Na ocasião, a aluna criadora da capa vencedora recebeu uma premiação e teve a honra de ter sua criação estampada na capa da coletânea. A escolha da ilustração foi feita pelas pesquisadoras e professores envolvidos no projeto.

Outros trabalhos produzidos de forma colaborativa, off-line, também foram criados para ser apresentados na culminância do Projeto, como cartazes produzidos pelos alunos sobre a vida e a obra do autor Júlio Verne, na disciplina de Língua Portuguesa, e simulação de uma erupção vulcânica na disciplina Ciências.

Na disciplina Língua Portuguesa, os temas biografia, teatro e seminário foram abordados em diferentes aspectos. Dentre os conteúdos abordados, os alunos que estudaram a biografia do autor Júlio Verne criaram textos de opinião e contos de ficção científica, prepararam apresentação de seminários de acordo com os assuntos estudados, e organizaram, ensaiaram e dramatizaram episódios do livro Viagem ao Centro da Terra.

\section{Conclusões}

A utilização da tecnologia digital, em algumas situações do projeto aqui investigado, facilitou o seu desenvolvimento, pois proporcionou meios favoráveis quando se pretendeu estender os temas abordados no Projeto, além dos muros da escola e horário das aulas.

As situações desenvolvidas durante o Projeto foram facilitadas pelo uso do laptop e suas possibilidades de mobilidade e conexão, que proporcionaram a realização de atividades nos ambientes colaborativos e recursos usados (Sócrates e ferramentas do Google Drive).

Essa extensão foi favorecida pelo uso do Sistema Online para Criação de Projetos e Comunidades (Sócrates) e com o uso de outras ferramentas online que favoreceram os processos de interação, criação, comunicação síncrona (comunicação em tempo real por meio de envios de mensagens instantâneas pelo meio digital. Ex.: mensagens de bate-papo, ligação telefônica) e assíncrona (comunicação em momentos e tempos diferentes, não simultaneamente. Ex.: email, fóruns) entre os sujeitos envolvidos no projeto.

A realização desta pesquisa evidenciou aspectos bastante relevantes em relação à colaboração e ao uso de recursos digitais como base para o desenvolvimento do processo de aprendizagem. A realização das atividades propostas durante o projeto analisado demonstrou o envolvimento entre os membros dos grupos e entre os grupos de forma a permitir que os alunos demonstrassem durante as atividades suas diversas habilidades, interesses, níveis de produtividade e atitudes comuns da vivência e trabalho em grupo. 
O trabalho proporcionou o estudo de conteúdos apresentados no currículo da escola através da realização de um projeto colaborativo usando tecnologia digital. Os alunos participantes da pesquisa puderam aprender, de forma diferenciada, conteúdos curriculares anteriormente explanados de forma instrucionista, caracterizados pela ausência de colaboração e realização de ações e aprendizagem em grupo.

\section{Referências}

ALMEIDA, M. E. B.; VALENTE, José Armando. (2011) Tecnologias e currículo: trajetórias convergentes ou divergentes? São Paulo: Paulus.

BEHRENS M A. Tecnologia interativa a serviço da aprendizagem colaborativa num paradigma emergente. (2005). Disponível em : <http://portal.mec.gov.br/seed/arquivos/pdf/2sf.pdf>. Ultimo acesso 20/10/013

BRASIL. (2008) Um Computador por Aluno: a experiência brasileira. Brasília: Câmara dos Deputados, Coordenação de Publicações, Série Avaliação de Políticas Públicas, n 1, 2008. Disponível em: http://bd.camara.gov.br. Acesso em: 15 set. 2011.

CASTELLS, M. (1999) A Era da Informação: economia, sociedade e cultura, vol. 3, São Paulo: Paz e terra, p. 411-439.

CASTRO FILHO, J A; ROCHA, B T S; VIANA, G; FREITAS, C; DAVID, P B. (2007) Guia didático - Projetos Colaborativos e Comunidades de aprendizagem. Fortaleza Tipogresso.

COLL, C; POZO, J E; SARABIA, B; VALLS, E. (1998) Os conteúdos na reforma: ensino e aprendizagem de conceitos, procedimentos e atitudes . Porto Alegre: Artes Médicas.

DAMIANI, T. M., SCHELEMMER, E. (2009) Trabalho colaborativo/ cooperativo em educação:uma possibilidade para ensinar e aprender. São Leopoldo.

MOLL, L C. (2005) Vygotsky e a Educação: Implicações pedagógicas da psicologia. Porto Alegre: Artes Médicas.

PONTES, R. L. J. (2011) O Uso da Web 2.0 na Educação: um estudo de caso com professores participantes do Projeto Um Computador por Aluno (UCA). Universidade Federal do Ceará. Dissertação de Mestrado.

PRIMO, A. (2007) O aspecto relacional das interações da web 2.0. E- Compós (Brasília), $\quad$ v. 9 9, p. $1-21$. Disponível em: http://www.moodle.ufba.br/file.php/10203/cultura_digital/web2_primo.pdf. Acesso em 17 dez 2012.

SILVA, K.S.A. (2011) Os Quatro Pilares: Reflexões Sobre a Educação no Século XXI. São Cristovão. Disponível em: $<$ http://www.educonufs.com.br/vcoloquio/cdcoloquio/cdroom/eixo\%202/PDF/Micro soft $\% 20$ Word $\% 20 \% 20$ OS $\% 20$ QUATRO $\% 20$ PILARES\%20REFLEX\%D5ES\%20S OBRE\%20A\%20EDUCA\%C7\%C3O\%20NO\%20S\%C9CULO \%20XXI.pdf $>$. Acesso em: 17 dez. 2012.

ZABALA, Antoni. (1998) A prática educativa: como ensinar. Porto Alegre: Artmed. 